\title{
Degendering Menstruation: Making Trans Menstruators Matter
}

\author{
Klara Rydström
}

\section{INTRODUCTION}

As scholars and activists we have the responsibility to continually evaluate the work we do. Within the field of critical menstruation studies, we must pay attention to our depictions of menstruation and menstruators, and the knowledge we produce in the pursuit to de-stigmatize menstruation. The recognition that not all women menstruate and not all who menstruate are women illustrates such an awareness. Yet, even though we know that menstruators are of various gender identities, there are few scholarly pieces with a focus on menstruators other than cis women. This chapter offers a theoretical intervention in the cisgendering of menstruation, informed by my own empirical work (Rydström 2018) and that of others (Bobel 2010; Chrisler et al. 2016; Fahs 2016; Berg 2017).

Within the framework of my MA thesis, I conducted qualitative interviews with nine Swedish trans people-self-defining as trans man (3), trans boy (1), trans guy (1), nonbinary and trans person (2), nonbinary and man ( 1 ), and trans person ( 1 - -about their experiences with menstruation. All participants were assigned-female-at-birth and either had an ongoing menstrual cycle and bleedings, or they had menstruated in the past. Based on the understanding of menstruation as often being cisgendered, I also attempted to understand what the participants believed must occur for a possible degendering of menstruation to happen (Rydström 2018).

Building on these findings, this chapter asserts that degendering menstruation is necessary for us to deal with menstrual shame, taboos, and stigmas in a gender-inclusive manner. Drawing on theoretical insights provided by post-constructionist theory ${ }^{1}$ (Lykke 2010) and transgender studies (Stone 2006; Stryker 1994; Nordmarken 2014; Preciado 2013), I suggest 
that a recognition of the multiplicity of menstrual realities among different menstruators, and non-menstruators, is key therein. Thus, the chapter elucidates various experiences with menstruation among trans people and casts light on areas wherein cis menstruators are made the normative menstruator and trans menstruators the Other.

\section{The 'Nature’ of Menstruation}

The cisgendering of menstruation is closely linked to the idea of nature as an ontological fact. Nature as given comes with the belief that certain bodies are closer to this naturalness than others; women are then commonly designated as the weaker sex because of their closeness to nature (Jackson and Falmagne 2013, 380). Women in general (Braidotti 1997, 59-80) and menstruating women in particular (Chrisler 2010, 204; Chrisler and Caplan 2012, 275, 283-84) are seen as monstrous because of their assumed lack of control over their unruly bodies. In a similar manner, references to nature are applied to build the argument that trans people hold monstrous bodies (Stryker 1994; Nordmarken 2014; Barad 2015). While cis women are perceived as monsters because of their supposed closeness to nature, the monstrosity of trans people derives from their assumed unnaturalness.

So, what is nature? The assumption that people necessarily belong to one of two gender categories-men and women-essentially linked with one of two sexed bodies - male and female-is based on a faulty ontology (Preciado 2013, 101-3). Following the post-constructionist theory, nature is inseparable from culture and the two are constituted in conjunction with one another; "[n]ature is neither a passive surface awaiting the mark of culture nor the end product of cultural performances" (Barad 2007, 183). Consequently, reality is not made up of discernible 'things,' given by nature or culture, but of material-discursive phenomena (Barad 2007, 139-40). As things, bodies, too, are phenomena and "it is through specific intra-actions ${ }^{2}$ that phenomena come to matter-in both senses of the word" (Barad 2007, 140). In other words, no body is more 'natural' than another, but all bodies are materially discursively constructed.

Within cisnormative contexts, cis bodies and trans bodies come to matter differently. Cisnormativity refers to the system of norms structuring societies according to the belief of sex/gender as binary where everyone is assumed to identify with the sex assigned to them at birth—an ideology and practice that divides all humans into the categories male/man or female/woman. Those who do not correspond to these structures are considered deviant (Nord, Bremer, and Alm 2016, 4-7). Cis bodies appear as fixed and given by nature - as compared to trans bodies defined by their expected physical modification and, therefore, unnaturalness (Finn Enke 2012, 6, 12).

Intra-actions determine what we perceive as a body and, specifically what we perceive as a menstruating body. Our identities, our bodies and regulative 
norm systems, intra-act and make menstruation appear as an experience natural to cis-female bodies, whereas it is considered unnatural to trans people who are seen as deviant/monstrous/Other. Thus, trans menstruators per se, are not only challenging, but actually materializing menstruation as other than ciswoman phenomena.

The potential for a degendering of menstruation is likewise found in the multiplicity of it as phenomena. By showing that no menstruating body is more natural than another, we can counter the Othering of trans menstruators based on the conception of unnaturalness (Stryker 2013, 149; Barad $2015,412-13)$. In my opinion, it is our responsibility as scholars and activists to do so; as part of the acknowledgment that there are no naturally preexisting boundaries of phenomena (Barad 2007, 139-40), I agree with post-constructionist scholars arguing that we are all accountable for the kind of phenomena we materialize (Barad 2003, 827; 2007, 90-91; Haraway $2016,7)$. Within the field of critical menstruation studies, our depictions of menstruation and menstruators, and the knowledge we produce to de-stigmatize and de-taboo menstruation, directly affect menstruation as phenomena-not only in discursive but also material terms.

One way to advance a more inclusive discourse and practice is to bring in voices of trans menstruators. This requires non-trans identified scholars and activists to decenter their own voices to make space for trans voices, though I assert that cisgender scholars and activists can make meaningful contributions. For one, scholars like me can offer critiques of menstruation as cisgendered phenomena, rather than represent 'truths' about trans menstruators. We can also change the way we talk about menstruation, including using the term menstruators, 'menstrual products' instead of 'feminine hygiene products' (Quint 2016) and rename 'female healthcare' centers with more gender-neutral terms (Rydström 2018, 74). After all, while these shifts can make trans menstruators matter, a degendering of menstruation will serve all of us, irrespective of identity and experience.

\section{Trans Experiences of Menstruating}

Menarche is commonly recognized as the moment where one goes from being a girl to becoming a woman (Hawkey et al. 2017; Jackson and Falmagne 2013; Rembeck 2008). Previous research has shown that menarche is perceived by some cis menstruators in positive terms, whereas others respond with more mixed feelings or resist the claims of womanhood (Jackson and Falmagne 2013, 382, 386-88). Equivalently, and not very surprisingly, trans menstruators' encounters with the first period vary as well. Some of my research participants stated that they remember it as a positive thing, whereas others recall how it marked them with a gender identity they do not identify with, especially through other people's new-found way of approaching them as women (Rydström 2018, 42-43; similar findings are 
made by Devor 1997 and Rubin 2003, cited in Bobel 2010, 161). While not all trans menstruators experience their menarche in negative terms, it seems fair to state that it is an event marked by cisnormativity.

Experiences of menstruating later in life vary among menstruators as well. Some do not suffer from their periods in direct relation to their gender identity. Others do, as they disidentify with the body as a whole and/or with certain body parts such as the genitalia or the uterus, or with the bodily function of menstruation. This suffering is sometimes related to gender dysphoria (Rydström 2018, 44-49). Notably, how gender dysphoria is experienced and felt is individual. Sade Kondelin (2017) has found that it is explained by many as "becoming conscious of one's embodiment [ . . . ] as gendered in a way that does not match one's sense of self" (26). As shown by participants in my study, for some menstruators that consciousness has to do with menstruation being cis-coded and, hence, mismatching with their trans-coded being. In practice, this means that some choose to stay at home when menstruating, either because the dysphoric feelings are too strong or to avoid any encounter that could trigger dysphoria (Rydström 2018, 44-45).

Not everyone experiences dysphoria in relation to their menstruation. Given that gender dysphoria is not only an embodied experience but also a diagnosis regulated by the World Health Organization's International Classification of Diseases (ICD) ${ }^{3}$ (World Health Organization 2018a), it is important to reckon with the diversity of experiences. Apart from enabling trans people to get access to gender-confirming treatments, the diagnosis contributes to the pathologization of their lives (Butler 2004, 4-5, 76). Previous studies indicate that some trans menstruators do not experience dysphoria but feel that they are seen by others as "not trans enough" (Berg 2017, 35; Rydström 2018, 49). Therefore, future studies should explore how transnormativity ${ }^{4}$ (Johnson 2016) shapes the experiences of trans menstruators.

Among those who do suffer from their menstruation, there are various ways to deal with their periods. In one study, trans menstruators are more positive toward menstrual suppression than cis menstruators (Chrisler et al. 2016, 1244). Aligned with such findings, testosterone treatments are a method adopted by some trans menstruators to get rid of unwanted bleeding. Preventing the menstrual period is not necessarily the main reason for using testosterone, but it can be one among several desired outcomes. Moreover, testosterone can help alleviate premenstrual symptoms and, as such, improve general well-being. For others, a side effect of testosterone is that it actually worsens well-being. One of my participants explained that healthcare personnel had proposed that he could adjust the dose, that is, lower it to not interfere with the mental health, while keeping it high enough to prevent his periods. Still, he told me, dealing with testosterone injections and keeping track of hormone levels is a more demanding alternative than menstruating (Rydström 2018, 52-53). Others choose to be on testosterone, while 
still keeping menstruation intact (Chrisler et al. 2016, 1241). I agree with Chrisler et al. $(2016,1241)$ who emphasize that research is needed to find out more about testosterone usage and menstruation.

What we do know is that not all who desire to suppress their menstruation are given access to testosterone. In Sweden, gaining access to testosterone requires assignment of the diagnosis "gender identity disorder, unspecified" (Transformering 2018). In other words, testosterone is not an alternative for menstruators outside the diagnostic framework. Moreover, nonbinary trans people who have been in touch with the trans-specific healthcare sector in Sweden have experienced their trans identity as discredited, as they do not fit into the binary idea of sex/gender (SOU 2017:92, 614-22). Similarly, my own research found that having a nonbinary gender identity can result in worries and anxiety for those who wish to get help from the healthcare sector to suppress their periods (Rydström 2018, 53). Here, it becomes evident that testosterone exists within a larger biopolitical framework wherein some bodies are considered more desirable — or more needy — than others (Preciado 2013), resulting in the regulated use of testosterone.

A common strategy to deal with unwanted menstruation is to choose menstrual products for their ability to conceal the periods. Some menstruators who feel aversion toward the genitalia, or toward penetration of the genitalia, prefer period-proof underwear (Chrisler et al. 2016, 1247) or pads, while others who find it distressing to feel to blood, and/or experiences pads as bulky, choose tampons as they keep the period less visible. The menstrual cup is used for the same reasons, or because tampons are physically uncomfortable (Rydström 2018, 54-55). Menstrual cups are sometimes preferred because the cup can stay within the body for a relatively long period of time once it is inserted and, thereby, does not require as many changes as tampons or pads (Chrisler et al. 2016, 1246; Fahs 2016, 82). Considering the long life span of a cup, it likewise minimizes the times one has to purchase menstrual products. Some trans menstruators find this beneficial as purchasing menstrual products in itself can be mentally demanding (Berg 2017, 25).

Menstrual blood, as opposed to venous blood, is commonly seen as differentiating women from men, a fluid seen as making the female body weak (Bramwell 2001, 89-90). It is abject, meaning it is "neither subject nor object" (Kristeva 1982, 1) and perceived with loathing and shame. Consequently, menstrual products are depicted as saving or protecting the body from blood and, as such, advertisements and commercials contribute to the objectification of women (Rosengarten 2000, 92-94, 99). Yet, for trans menstruators suffering from their periods, menstrual blood can be more than a bodily fluid charged with societal shame; the blood may be a reminder of a body, a body part, or a bodily function they do not identify with (Rydström 2018, 57-58). Thus, it must be acknowledged that for some menstruators, menstrual products can be a rescue, just because the right product keeps the unwanted blood at a distance. 
Other trans menstruators deal with unwanted periods by subverting the meaning of menstruation. For example, the blood can be visualized as making oneself manlier (Fahs 2016, 83-84). One of my research participants explained that putting on a specific pair of briefs helped him look upon his bleedings as a superpower making him special, as compared to other men. Another participant understood menstruation as a sign of bodily health (Rydström 2018, 51-52). Moreover, some of the people I interviewed indicated that they had become comfortable in their bodies over time and, in doing so, improved their perception of their periods (Rydström 2018, 46-47). Such subversive efforts can be seen as abjectification, that is, processes wherein the abject is reclaimed and reidentified by the abject-holders themselves. For some, abjectification is a strategy of resistance toward the system which oppresses them, for others it is simply a question of survival (Wasshede 2017, 35, 48). But for some trans menstruators, the only way out is to simply ignore and mentally repress unwanted periods (Rydström 2018, 52 ). Each of these examples makes clear that menstruation as phenomena are not fixed but vary among menstruators and across time.

\section{Menstruators, Not Menstruating Women}

The term 'menstruator' likely comes as no surprise for any critical menstruation scholar. Chris Bobel's use is prominent, with her book New Blood: Third-Wave Feminism and the Politics of Menstruation (2010) underlining how the term "expresses solidarity with women who do not menstruate, transgender men who do, and intersexual and genderqueer individuals" (12). Here, it is clear that a move beyond the perception of menstruation as a female experience not only functions to make our work inclusive of trans and intersex people, but the menstruator term likewise substantiates theorizing around the fact that not all women menstruate, for example, trans women, postmenopausal women, pregnant women, and those experiencing amenorrhea. I would like to stretch it further to state that the menstruator term is a foundational part of our terminology; it captures the critical engagement driving the field of menstruation studies.

Referring to people who menstruate as 'menstruators' does not come without criticism. Related to a more general debate within feminism(s), the term reifies the question: is it possible to make resistance toward patriarchal structures while leaving behind the term 'woman?' Here, the division between those aligning with sexual difference theory-stressing the necessity of the categorical label 'women'-versus those aligning with gender theory-recognizing gender as a construct-is made explicit (Bobel 2010, 155-56). Nevertheless, taking into consideration that "transsexual lives are lived, hence livable" (Scheman, quoted in Stone 2009), the perceived issue at stake becomes a nonissue. Menstruators are of a variety of gender identities (far beyond those who identify as trans) and, hence, menstruation cannot 
be equated singularly with cis/womanhood. To argue otherwise would be to ascribe menstruation to a biologically essentialist idea of corporeality.

As a development of the menstruator term, we can talk about cis menstruators and trans menstruators, the latter as expressed through some menstrual activism (Toni the Tampon 2017) as well as in children's books (Cairney 2017). While the cis menstruator term is not as recognized, I would like to emphasize its usefulness. The two terms allow us to explore what it means to be a menstruator within cisnormative contexts. It is important to note, however, the vast diversity of menstrual experiences across the gender spectrum. There is no uniform menstrual reality for trans or cis menstruators. Thus, the two menstruator terms should be considered conceptual tools applicable to critical explorations of menstruation as cisnormative phenomena; they should not be applied to make assumptions about menstrual experiences based on gender identity.

\section{Cis Menstruators as the Normative Menstruator, Trans Menstruators as the OTher}

Taken together, the cis menstruator and trans menstruator terms facilitate analyses of menstruation as phenomena affecting different menstruators in different ways. This terminology means that we should not focus exclusively on the supposed Other but, rather, recognize the power relations and structures underlying menstruation. Josefin Persdotter's concept of menstrunormativity, (Chapter 29, this volume) makes visible the processes through which certain menstruators (and menstruations) are seen as the 'right' ones, whereas others are considered 'wrong.' She further states that menstrunormativity could be thought of as a conceptual sibling to cisnormativity and heteronormativity (Persdotter 2020). Heteronormativity builds on the assumption of people being heterosexual and, hence, desiring people of 'the opposite' sex/gender. Affecting not only non-heterosexual people, heteronormativity impinges upon societies as a whole (Herz and Johansson 2015, 1012). Considered together, menstrunormativity, cisnormativity, and heteronormativity intra-act, and are mutually reinforcing, in the Othering of trans menstruators within various areas related to menstruation.

One such area is menstrual activism. Even though the existence of trans menstruators has been raised within activism by trans people themselves-for example, Cass Bliss, who does prominent work spreading awareness through social media-trans menstruators are not represented within menstrual movements in general. As briefly mentioned, Bobel (2010) points out that for many activists, the question of trans inclusion in menstrual activism comes down to the same question as is present in many other feminist movements, namely: "[w]hat should feminists do about the category 'woman'? [ . . . ] work within it or destroy it?" (156). If we abolish the category 'woman' and thus, detach menstruation from gender, can we still claim that menstruators 
are oppressed because the meaning of menstruation is shaped by the devaluation of women qua women? I believe that I have already answered this question. Because some trans people do menstruate, they must be recognized within any menstrual activist agenda. The truth lies at the surface of the body. Our menstrual discourse must include all bodies that menstruate, as well as all non-menstruating bodies that are affected by menstrual norms, regardless of gender identity. It might just be that simple.

Cisnormativity and menstrunormativity as norm systems are both detectable within menstrual activism. Menstruation as phenomena are surrounded by stigma; menstrual blood is commonly depicted as something that should be kept within the body and, thereby, menstruators are encouraged to conceal their periods (Johnston-Robledo and Chrisler 2013, 11). Menstruating women can feel united through this shared experience of periods as a private matter that should be publicly undetectable (Brantelind, Nilvér, and Alehagen 2014, 611). One of my participants expressed that the menstrual concealment results in 'female' rooms becoming a safe space to discuss menstruation, as that is where one is free from the stigmatizing public jargon. Correspondingly, another participant emphasized that, in general, it is only cis women who participate within menstrual activism. In their own experience, doing menstrual activism has resulted in disapproval from other activists, just because they are not a woman (Rydström 2018, 59, 63). Gender norms and menstrual norms intra-act within menstrual activism, resulting in it being represented by, and representing, cis menstruators.

Public bathrooms constitute a second area wherein trans menstruators are Othered. Public bathroom access is commonly debated when discussing the living conditions of trans people in the Global North (Halberstam 2018, 133-35). Bathroom access is, of course, an especially acute issue for trans and nonbinary menstruators, per se. Chrisler et al. (2016) report that more than $60 \%$ of their 150 participants, all belonging to the masculine of center and transgender community, feel unsafe and/or uncomfortable when using a "men's room" during their periods (1246). One of the informants in Breanne Fahs' essay "The Menstruating Male Body" (2016) raises the same issue when declaring a fear of changing tampons in public bathrooms as it potentially will "out" him as trans (82). Evidently, the issue is deeper than a dispute over access to bathrooms, it is a question of trans people's health and safety (Schuster, Reisner, and Onorato 2016). Given that menstruation requires regular visits to bathrooms, it is imperative to include trans menstruators in future discussions on the topic.

Just as within menstrual activism, cis norms and menstrual norms intraact in the Othering of trans menstruators within the area of public bathrooms. The lack of menstrual infrastructure within the 'men's room,' such as basins and bins to wash or toss menstrual products, is not only a practical issue affecting the individual menstruator. It likewise materializes the normative assumption that menstruators use the 'women's room.' As a result, 
trans menstruators who prefer to use the 'men's room' are challenging the binary and risk being seen as abject (Cavanagh 2013, 433-36). An anecdote told by one of the trans menstruators I interviewed, Mika, indicates that the issue is even more complex. Mika once visited a 'men's room' on his period where the menstrual infrastructure actually was in place. Yet, he did not dare to use the bin as he was afraid it would not be emptied, and he feared that his bloody menstrual product would eventually start to smell (Rydström 2018, 61). Generally speaking, menstrual blood in itself is perceived as dirty/ unclean/impure (Bramwell 2001, 90-93) and it seems perceived as even more abject when the menstruator is non-conformant to the idea of menstruation as a female experience.

Menstrual products represent the third area wherein trans menstruators are being Othered. Scholars have critically examined the representation of menstrual products as mutually constitutive of menstrual stigma and taboo; pads and tampons are depicted as keeping the menstrual blood at a distance (Erchull 2013), protecting menstruators from leakage, and keeping the body in control (Rosengarten 2000, 92-96). The blue liquid in advertisements, supposedly representing menstrual blood, is a well-known example of such discourses ${ }^{5}$ (Merskin 1999, 955). To quote Persdotter (2020): “[ $\mathrm{m}]$ enstrunormativity is built into menstrual technologies" (p. 357) and, as explained below, the business of menstrual products materializes cis menstruators as the normative menstruator.

The Othering of trans menstruators in relation to menstrual products is present on various levels. Firstly, the framing of products reveals who is counted as a menstruator. The term 'feminine hygiene products' is commonly applied to label pads/tampons/cups/period underwear/et cetera, while some activists use 'menstrual products' as a gender-neutral alternative (Quint 2016). As confirmed by my own research, some trans menstruators feel invisible when looking for information about menstrual products, just because many companies target girls and women. Relatedly, the packaging of menstrual products-feminine-coded colors and patterns-can cause discomfort to people who do not identify with femininity (Rydström 2018, 59-60). The design of the products themselves, specifically the design of pads, is likewise part of the Othering. Pads are predominantly designed to fit to panties and, hence, are difficult to use for menstruators who prefer briefs or boxers (Rydström 2018, 60; The Period Prince 2018). The company Pyramid Seven, with their "boxer briefs for periods, not for gender" (Pyramid Seven, n.d.), offers an alternative. However, they are an exception within a generally cisnormative industry.

The healthcare sector constitutes the final area I note wherein trans menstruators are Othered. It has been shown that some menstruators fear healthcare personnel's lack of knowledge and transphobic reception (Chrisler et al. 2016, 1239, 1247; Rydström 2018, 62-63) and, at a closer look, this can be intertwined with context-specific concerns. Taking Sweden as 
an example, the gendering of personal identity numbers ${ }^{6}$ is a general issue affecting trans people in various societal instances (SOU 2017:92, 173) and testimonies of trans menstruators indicate that the numbers result in healthcare workers having preconceived ideas about patients before they enter the room. This is expressed in transphobic and heterosexist treatments (Rydström 2018, 62-63). Another issue applicable to the Swedish context is the naming of clinics focused on sexual and reproductive issues; the label kvinnokliniker ("women's clinics") not only affects trans people seeking pregnancy health services (SOU 2017:92, 724) but it likewise makes some trans people hesitant to contact the clinics with menstrual-related issues (Rydström 2018, $63,71)$. Cisnormativity and heteronormativity clearly play an important role in the Othering of trans menstruators within the Swedish healthcare sector, and I hypothesize that this complex of problems is applicable to other geographical contexts as well.

When cis and trans menstruators are seen as binary categories given by nature, the intra-actions of cisnormativity, heteronormativity, and menstrunormativity make cis women the normative menstruator, a standard against which trans menstruators (as in non-cis menstruators) are deviant. In the contexts of menstrual activism, cisgendered public bathrooms, the design and marketing of menstrual products, and the failure of the healthcare sector to be trans inclusive, menstruation as cis-female phenomena are reinscribed. In other words, trans menstruators are being Othered as their existence challenges prevalent perceptions of menstruation.

\section{The Intersection of Critical Menstruation Studies And Transgender Theory}

Recognizing critical menstruation studies as an interdisciplinary field, I suggest that the theoretical framework of transgender studies is useful to make our work more inclusive. Sandy Stone (2006), one of the first scholars of transgender studies, criticizes the ways in which trans people have often been theorized by the medical establishment as unnaturally embodied. Constrained by such narratives, they adapt and align with the norms by which they are subordinated and admit their Otherness. Thus, she stresses, by drawing on their embodiment and experiences, trans people can redefine their existence and efficiently disrupt conventional ideas of gender (230-31). Along this line, trans scholars have associated trans bodies with monstrous bodies; trans people have been perceived as nonhuman freaks by non-trans scholars-Janice Raymond with her book The Transsexual Empire (1979) is probably the most well-known of these-but this monstrosity has likewise been reclaimed by some trans people themselves. The concept of monstrosity, and transgender theory in general, questions the idea of nature, a nature which trans people are perceived to violate. It is described by trans scholars as birthing 
a productive rage toward the system of norms which Others them (Stryker 1994; Nordmarken 2014).

There are similarities between transgender theory and previous explorations of menstruation. Here, I am aligning with the post-constructionist (Lykke 2010) strand of critical menstruation scholars, such as Jessica Shipman Gunson (2016) and Katie Ann Hasson (2016), who demonstrate that menstruation as phenomena are material-discursive; menstruation (or its lack) is perceived and experienced in a variety of ways and, hence, there is nothing singular in its being. Rather, menstruation is multiple. For instance, some menstruators differentiate menstruation-as 'natural'-from menstrual suppression-as 'unnatural.' Others consider suppressing bleeding just as natural as bleeding, and some do not even think in terms of naturalness versus unnaturalness. Thus, it would be inadequate to argue that something is intrinsically natural/unnatural when it comes to menstruation because the conceptualizations vary (Shipman Gunson 2016, 317-20). Similar to how transgender scholars challenge prevalent perceptions of nature, we can confront the idea of menstruation as a natural female experience by exploring the plurality of menstruation.

While pointing out the usefulness of transgender theory for critical menstruation studies, I also acknowledge my own social location. I am not trans. Historically, trans people have been denied the space and authority to conduct research and build theory about their lives (Stone 2006, 229-30). Today, this discrepancy persists. Similar to Bobel (2010), I have been struggling with these thoughts. Initially, when conducting research for New Blood, she intended to interview trans people. Yet, aiming to be a responsible trans ally, she decided not to carry forward her quest in response to the feedback she received from trans identified people she consulted regarding her project (161-63). I received different feedback and made a different choice (Rydström 2018). I still do not know if it was a proper one.

However, my main point is to bring forward the argument that we-as scholars and activists - can make our work inclusive of a variety of menstruators, and non-menstruators, by questioning continuously the nature of menstruation. Here, Jacob Hale's advice to non-trans identified writers to "[f]ocus on: what does looking at transsexuals, transsexuality, transsexualism, or transsexual tell you about *yourself*, " not $^{*}$ what does it tell you about trans" (Hale, quoted in Stone 2009 ) provides productive guidance. What does looking at trans experiences with menstruation tell us about menstruation per se? By looking at trans and nonbinary people's experiences with menstruation, or the experiences of menstruators belonging to other gender categories, the multiplicity of menstruation is articulated. This tells us that there is no given relationship between menstruation and cis/womanhoodan observation that efficiently facilitates the degendering of menstruation as phenomena. 


\section{Notes}

1. Nina Lykke (2010) coined the term "post-constructionism" to label the group of heterogeneous theories moving beyond biological essentialism and social constructionism. Different terms have been applied by other scholars to refer to the same kind of theories and theorists, for example, "material feminisms" (Alaimo and Hekman 2008).

2. "Intra-action" refers to relational movements between human as well as nonhuman agents. Different from "interaction"-which occurs between ontologically independent entities - such agents are intertwined and do not exist outside of one another (Barad 2007, 139-40).

3. At present, gender dysphoria is labeled as a mental health condition. With the new edition, the ICD 11 , it will be placed under the umbrella term "sexual health." These changes will be formally presented in 2019 and set into motion in 2022 (WHO 2018b).

4. Transnormativity refers to the system of norms structuring the lives of trans people through privileging certain narratives. The medicalization narrative is one such stipulation, assuming that all trans people wish to reshape their bodies. Trans people who do not desire a medical transition hence break with the normative idea of what makes a trans person (Johnson 2016, 465-66, 468-69).

5. The Body Form commercial series "Blood Normal," making visible a red liquid, suggests a change may be on its way (Libresse 2016).

6. In Sweden, one is either assigned a female personal identity number, where the second to last number is even, or a male number, where the second to last number is uneven (SOU 2017:92, 173).

\section{REFERENCES}

Alaimo, Stacy, and Susan Hekman, eds. 2008. Material Feminisms. Bloomington and Indianapolis: Indiana University Press.

Barad, Karen. 2003. "Posthumanist Performativity: Toward an Understanding of How Matter Comes to Matter." Signs: Journal of Women in Culture and Society 38 (3): 801-31.

- 2007. Meeting the Universe Halfway: Quantum Physics and the Entanglement of Matter and Meaning. Durham and London: Duke University Press.

—. 2015. "Transmaterialities: Trans*/Matter/Realities and Queer Political Imaginings." GLQ: A Journal of Lesbian and Gay Studies 21 (2-3): 387-422. https://doi.org/10.1215/10642684-2843239.

Berg, Beatrice. 2017. "Transgendering Menstruation: en kvalitativ studie av uppfattningar kring menstruation i relation till transidentitet i Sverige." BA thesis, University of Gothenburg.

Bobel, Chris. 2010. New Blood: Third-Wave Feminism and the Politics of Menstruation. New Brunswick, NJ and London: Rutgers University Press.

Braidotti, Rosi. 1997. "Mothers, Monsters, and Machines." In Writing on the Body: Female Embodiment and Feminist Theory, edited by Katie Conboy, Nadia Medina, and Sarah Stanbury, 59-80. New York: Columbia University Press. 
Bramwell, Ros. 2001. "Blood and Milk: Constructions of Female Bodily Fluids in Western Society." Women and Health 34 (4): 85-96. https://doi.org/10.1300/ J013v34n04_06.

Brantelind, Ida Emelie, Helena Nilvér, and Siw Alehagen. 2014. "Menstruation during a Lifespan: A Qualitative Study of Women's Experiences." Health Care for Women International 35 (6): 600-16. https://doi.org/10.1080/07399332. 2013.868465 .

Butler, Judith. 2004. Undoing Gender. New York and Abington: Routledge.

Cairney, Gemma. 2017. Open: A Toolkit for How Magic and Messed Up Life Can Be. Basingstoke: Pan Macmillan.

Cavanagh, Sheila. 2013. "Touching Gender: Abjection and the Hygienic Imagination." In The Transgender Studies Reader 2, edited by Susan Stryker and Aren Z. Aizura, 426-42. New York and London: Routledge.

Chrisler, Joan C. 2010. "Leaks, Lumps, and Lines: Stigma and Women's Bodies." Psychology of Woman Quarterly 35 (2): 202-14. https://doi. org/10.1177/0361684310397698.

Chrisler, Joan C., Jennifer A. Gorman, Jen Manion, Michael Murgo, Angela Barney, Alexis Adams-Clark, Jessica R. Newton, and Meaghan McGrath. 2016. "Queer Periods: Attitudes toward and Experiences with Menstruation in the Masculine of Centre and Transgender Community." Culture, Health \& Sexuality 18 (11): 1238-50. https://doi.org/10.1080/13691058.2016.1182645.

Chrisler, Joan C., and Paula Caplan. 2012. "The Strange Case of Dr. Jekyll and Ms. Hyde: How PMS Became a Cultural Phenomenon and a Psychiatric Disorder.” Annual Review of Sex Research 13 (1): 274-306.

Erchull, Mindy J. 2013. "Distancing through Objectification? Depictions of Women's Bodies in Menstrual Product Advertisements." Sex Roles 68 (1-2): 32-40. https://doi.org/10.1007/s11199-011-0004-7.

Fahs, Breanne. 2016. Out for Blood: Essays on Menstruation and Resistance. Albany: State University of New York Press.

Finn Enke, Ann, ed. 2012. Transfeminist Perspectives in and Beyond Transgender and Gender Studies. Philadelphia: Temple University Press.

Halberstam, Jack. 2018. Trans*: A Quick and Quirky Account of Gender Variability. Oakland: University of California Press.

Haraway, Donna J. 2016. Manifestly Haraway. Minneapolis: University of Minnesota Press. ProQuest Ebook Central.

Hasson, Katie Ann. 2016. "Not a "Real" Period? Social and Material Constructions of Menstruation." Gender \& Society 30 (6): 958-83. https://doi. org/10.1177/0891243216672662.

Hawkey, Alexandra J., Jane M. Ussher, Janette Perz, and Christine Metusela. 2017. "Experiences and Constructions of Menarche and Menstruation among Migrant and Refugee Women." Qualitative Health Research 27 (10): 1473-90. https:// doi.org/10.1177/1049732316672639.

Herz, Marcus, and Thomas Johansson. 2015. "The Normativity of the Concept of Heteronormativity." Journal of Homosexuality 62 (8): 1009-20. https://doi.org/ 10.1080/00918369.2015.1021631.

Jackson, Theresa E., and Rachel Joffe Falmagne. 2013. "Women Wearing White: Discourses of Menstruation and the Experience of Menarche." Feminism \& Psychology 23 (3): 379-98. https://doi.org/10.1177/0959353512473812. 
Johnson, Austin H. 2016. "Transnormativity: A New Concept and Its Validation through Documentary Film about Transgender Men*." Sociological Inquiry 86 (4): 465-91.

Johnston-Robledo, Ingrid, and Joan C. Chrisler. 2013. "The Menstrual Mark: Menstruation as Social Stigma." Sex Roles 68 (1-2): 9-18. https://doi. org/10.1007/s11199-011-0052-z.

Kondelin, Sade. 2017. "If I Could Touch It, It Would Be Something Sticky and Cold': Gender Dysphoria as an Embodied Experience." Lambda Nordica 22 (1): $15-37$.

Kristeva, Julia. 1982. Powers of Horror: An Essay on Abjection. New York: Columbia University Press.

Libresse Sverige. "Libresse Blood.” Youtube Video, 26 April, 2016. Accessed March 17, 2018. https://youtu.be/sL2xE5kkL_Q.

Lykke, Nina. 2010. "The Timeliness of Post-Constructionism." NORA-Nordic Journal of Feminist and Gender Research 18 (2): 131-36. https://doi.org/10.1080/08038741003757760.

Merskin, Debra. 1999. "Adolescence, Advertising, and the Ideology of Menstruation." Sex Roles 40 (11-12): 941-57.

Nord, Iwo, Signe Bremer, and Erika Alm. 2016. "Redaktionsord: Cisnormativitet och feminism." Tidskrift för Genusvetenskap 37 (4): 2-14.

Nordmarken, Sonny. 2014. "Becoming Ever More Monstrous: Feeling Transgender In-Betweenness." Qualitative Inquiry 20 (1): 37-50. https://doi. org/10.1177/1077800413508531.

Persdotter, Josefin. 2020. "Introducting Menstrunormativity: Towards a Complex Understanding of 'Menstrual Monsterings'.” In The Palgrave Handbook of Critical Menstruation Studies, edited by Chris Bobel, Inga Winkler, Breanne Fahs, Katie Ann Hasson, Elizabeth Kissling, and Tomi-Ann Roberts. Palgrave MacMillan.

Preciado, Paul. 2013. Testo Junkie: Sex, Drugs, and Biopolitics in the Pharmacopornographic Era. New York City: Feminist Press.

Pyramid Seven. n.d. "Pyramid Seven." Accessed June 7, 2018. https://www.pyramidseven.com.

Quint, Chella. 2016. "Queeriods.” Accessed May 31, 2018. https://periodpositive. files.wordpress.com/2016/02/queeriods-lgbt-stem-poster-feb-2016.pdf.

Raymond, Janice. 1979. The Transsexual Empire: The Making of the She-Male. Boston: Beacon Press.

Rembeck, Gun. 2008. “The Winding Road to Womanhood: Adolescents' Attitudes towards Menstruation, Womanhood and Sexual Health-Observational and Interventional Studies." PhD diss., University of Gothenburg.

Rosengarten, Marsha. 2000. "Thinking Menstrual Blood." Australian Feminist Studies 15 (31): 91-101.

Rydström, Klara. 2018. "Trans Menstruators Matter: A Qualitative Research Exploring Swedish Trans Experiences with Menstruation.” MA thesis, University of Oviedo and University of Hull.

Schuster, Mark A., Sari L. Reisner, and Sarah E. Onorato. 2016. "Beyond Bathrooms-Meeting the Health Needs of Transgender People." New England Journal of Medicine 375 (2): 101-3. 
Shipman Gunson, Jessica. 2016. "Nature, Menstrual Suppression, and the Value of Material Feminism.” Health Sociology Review 25 (3): 312-25. https://doi.org/10. 1023/A:1018881206965.

SOU 2017:92. Transpersoner $i$ Sverige: Förslag för stärkt ställning och bättre levnadsvillkor.

Stone, Sandy. 2006. "The Empire Strikes Back: A Posttransexual Manifesto." In The Transgender Studies Reader, edited by Susan Stryker and Stephen Whittle, 221-35. New York and London: Routledge.

—. 2009. "Suggested Rules for Non-Transsexuals Writing about Transsexuals, Transsexuality, Transsexualism or Trans ." Accessed November 16, 2018. https://sandystone.com/hale.rules.html.

Stryker, Susan. 1994. "My Words to Victor Frankenstein above the Village of Chamounix: Performing Transgender Rage." GLQ 1 (3): 237-54. https://doi. org/10.1215/10642684-1-3-237.

. 2013. "Trans Health Is Queer (and Queer Health Isn't Normal)." Lambda Nordica 18 (3-4): 147-65.

The Period Prince. 2018. "Rainbow Reviews: GladRags." Accessed June 7, 2018. https://www.bleedingwhiletrans.com/single-post/2018/05/21/RainbowReviews-GladRags.

Toni the Tampon (@tonithetampon). 2017. "The Christian Post Calls My Move to Include Trans and Queer Menstruators 'Child Abuse'." Instagram Photo, March 10, 2017. https://www.instagram.com/tonithetampon/.

Transformering. 2018. “Underlivskirurgi." Accessed May 23, 2018. http://www. transformering.se/vardhalsa/hormoner.

Wasshede, Cathrin. 2017. "Queer Hate and Dirt Rhetoric: An Ambivalent Resistance Strategy." Journal of Resistance Studies 3 (1): 29-61.

World Health Organization. 2018a. "Classifications." Accessed April 28, 2018. http://www.who.int/classifications/icd/icdonlineversions/en/.

- 2018b. "WHO Releases New International Classification of Diseases (ICD 11)." Accessed June 25, 2018. http://www.who.int/news-room/ detail/18-06-2018-who-releases-new-international-classification-of-diseases-(icd-11).

Open Access This chapter is licensed under the terms of the Creative Commons Attribution 4.0 International License (http://creativecommons.org/licenses/ by $/ 4.0 /$ ), which permits use, sharing, adaptation, distribution and reproduction in any medium or format, as long as you give appropriate credit to the original author(s) and the source, provide a link to the Creative Commons license and indicate if changes were made.

The images or other third party material in this chapter are included in the chapter's Creative Commons license, unless indicated otherwise in a credit line to the material. If material is not included in the chapter's Creative Commons license and your intended use is not permitted by statutory regulation or exceeds the permitted use, you will need to obtain permission directly from the copyright holder.

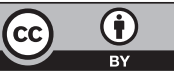

